\title{
Contrasting effects of acute and chronic treatments with ketamine on inhibitory avoidance and escape latency in the elevated-t-maze
}

\author{
Adegbenga Rotimi OWOLABI ${ }^{1 *}$ and Moses Atanda AKANMU ${ }^{2}$ \\ ${ }^{I}$ Department of Medical Pharmacology and Therapeutics, Faculty of Basic Medical Sciences, \\ Obafemi Awolowo University, Ile-Ife, Osun State, Nigeria. \\ ${ }^{2}$ Department of Pharmacology, Faculty of Pharmacy, Obafemi Awolowo University, \\ Ile-Ife, Osun State, Nigeria. \\ *Corresponding author,E-mail: rolabi07@yahoo.com,rowlacom@gmail.com; \\ Tel: +2348037158864. P.O. Box 849, Ota, Ogun state, Nigeria.
}

\begin{abstract}
Previous studies have suggested the involvement of N-Methyl,D-Aspartate (NMDA) pathway in the Pathophysiology of anxiety disorder. However the role of NMDA neurotransmission in the neurobiology of different classes of anxiety disorder remains unexplored. This study examined the effects of intraperitoneal administration of acute $(3 \mathrm{mg} / \mathrm{kg})$ and withdrawal from chronic administration of non-competitive NMDA receptor antagonist - ketamine (15 mg/kg daily for 21 days and withdrawn for 24 hours) on inhibitory avoidance duration (conditioned fear related behaviour) and escape latency (unconditioned fear related behaviour) using the elevated-T-maze $(\mathrm{ETM})$ in mice $(\mathrm{n}=10)$. The results showed that acute ketamine reduced while withdrawal from chronic ketamine administration increased inhibitory avoidance duration significantly ( $\mathrm{p}<0.05)$. Acute ketamine also increased escape latency, but withdrawal from chronic ketamine reduced escape latency significantly $(\mathrm{p}<0.05)$. It was inferred that acute ketamine decreased conditioned and unconditioned fear related behaviours as a result of NMDA transmission downregulation, while withdrawal from chronic ketamine induced increase in conditioned and unconditioned related behaviours via NMDA transmission upregulation. Changes in NMDA transmission appear to be relevant in the neurobiology of generalized anxiety disorder and panic disorder related behaviours in the ETM, hence pharmacological modulation of NMDA transmission may contribute to improved treatment of generalised anxiety and panic disorders.
\end{abstract}

(C) 2014 International Formulae Group. All rights reserved.

Keywords : N-Methyl,D-Aspartate, upregulation, downregulation, neurotransmission.

\section{INTRODUCTION}

Clinical anxiety disorder is heterogeneous, comprising generalised anxiety disorder, panic disorder, obsessive compulsive disorder, specific phobia, posttraumatic stress disorder and social anxiety disorder (APA 1994). Different animal models have been developed to study each of the anxiety disorders at the preclinical level (Graeff and Del-Ben, 2008, Johnson et al., 2012). Specifically, the elevated T-maze (ETM) was developed by Graeff et al. (1998) to assess two types of anxiety-related behavioural tasks (acquisition of inhibitory 
avoidance and escape latency). The ETM consists of three elevated arms, one enclosed and two open. Inhibitory avoidance representing learned or conditioned fear is the time taken to leave the enclosed arm in three consecutive trials. Unconditioned fear is the time to escape from the open arm (Graeff et al., 1998). Results of previous behavioural and pharmacological profile of the ETM support the view that inhibitory avoidance (conditioned fear) in the elevated T-maze is related to generalized anxiety disorder, while one-way escape (unconditioned fear ) is associated with panic disorder (Graeff et al., 2002).

Several neurotransmitter systems including the NMDA transmission have been implicated in the neurobiology of anxiety disorders (Garakin et al., 2006; Amiel and Sanjay, 2007; Davis, 2011). However the exact role of NMDA transmission on different types of anxiety disorders has not been explored. Hence this study intends to investigate the role of NMDA transmission in two types of experimental anxiety (conditioned - passive avoidance and unconditioned - one way escape) using the elevated T-maze and pharmacological tools (ketamine - a non-competitive NMDA receptor antagonist). The result of this study is expected to suggest the possible role of NMDA transmission in conditioned and unconditioned fear related behaviours, thus contributing to the existing knowledge on the neurobiology and possible improved treatment outcome of anxiety disorder.

\section{MATERIALS AND METHODS}

Animals

Adult albino mice (20-30 g), used for all investigations were bred and housed in a well ventilated room, maintained under a natural dark/light cycle, ambient temperature of $28 \pm 2{ }^{\circ} \mathrm{C}$ and were allowed food and water ad libitum. Animals were kept in cubic plastic cages $(25 \mathrm{~cm} \mathrm{X} 16 \mathrm{~cm} \mathrm{X} 12 \mathrm{~cm})$, with a wire mesh top surface for maximal ventilation and illumination. In all, ten animals comprising equal number of males and females were used per group. The experimental protocols followed the internationally accepted principles for laboratory animal use and care (EEC directive of 1986; 86/609/EEC).

\section{Drugs}

Ketamine (Rotex Medica, Trittau, Germany) was used. The drug was dissolved in normal saline as the vehicle for intraperitoneal administration (i.p.). Drugs used were delivered to the animals intraperitoneally at volume of $10 \mathrm{mls} / \mathrm{kg}$ body weight. The drug dosages were chosen based on previous studies (Hyung-Wook et al., 2009).

\section{Drug treatment protocol for assessment of inhibitory avoidance duration and escape latency}

The following treatment protocol was employed for this study. Animals were randomly divided into 4 groups of 10 animals each. Groups 1 and 2 were used for the acute drug treatment while groups 3 and 4 were subjected to chronic drug treatment as indicated below.

Acute drug treatments:

Group 1 saline (10 mls/kg, i.p.)

Group 2. ketamine (3 $\mathrm{mg} / \mathrm{kg}$, i.p.)

Chronic drug treatment

Group 3. saline (10 mls/kg, i.p.) daily for 21

days

Group 4. ketamine (15 mg/kg, i.p.) daily for 21 days.

The elevated T-maze for assessment of inhibitory avoidance duration and escape latency

The T-maze was made of wood, and had three arms of equal dimensions ( 30 X 5 $\mathrm{cm})$. One arm, enclosed by walls $20 \mathrm{~cm}$ high, was perpendicular to two opposed open arms. To avoid falls, the open arms were surrounded by a $0.5 \mathrm{~cm}$ high wooden rim. The whole 
apparatus was elevated $50 \mathrm{~cm}$ above the floor (Graeff et al., 1993).

\section{Assessment of inhibitory avoidance duration and escape latency using the elevated T-maze}

Assessment of the inhibitory avoidance and escape latency was conducted according to the methodology of Graeff and co-workers (1993). On the second and third days after their arrival in the laboratory, the animals were gently handled for 10 minutes. On the fourth day, all animals were exposed to one of the open arms of the elevated T-maze (ETM) for $30 \mathrm{~min}$. Wood barriers mounted on the border of the maze central area and the arm's proximal end isolated the open arm of the ETM. Exposure of the mice to the open arms of the ETM being a novelty to the mice, is expected to induce exploratory behaviour including increase in their locomotor activity (Tchernikovski and Golani, 1995). It has been reported that this exploratory activity interferes with escape latency in naive animal (Graeff et al., 1993). The pre-test exposure to open arms of the ETM was done 24 hours prior to conduct of the acute and chronic studies. Pre-test exposure (training) of the animals to the open arm of the elevated $\mathrm{T}$ maze for 10 minutes, 24 hours before the test leads to habituation of exploration, thus eliminating the influence of novelty on the escape latency. Withdrawal from the open arm following pre-test exposure was suggested as a better index of escape latency (Graeff et al., 1998).

The elevated T-maze test was performed $24 \mathrm{hrs}$ after the pre-test exposure. Five minutes after acute drug or vehicle treatment and $24 \mathrm{hrs}$ after the last dose of chronic drug or vehicle treatment, animals were placed at the distal end of the enclosed arm facing the intersection of the arms. The mouse was left alone until it leaves the enclosed arm with its four paws. The same procedure was repeated twice at 30-s intervals. The time taken for the animal to leave the enclosed arm at each trial was recorded as the inhibitory avoidance duration (IAD). One minute after the conclusion of the inhibitory avoidance session, the mouse was placed at the end of the open arm and the time taken to leave the arm with the four paws was recorded (escape latency - EL).

\section{Statistical analysis}

The results were presented as means \pm standard error of means. The significance of changes in inhibitory avoidance duration and escape latency between control and experimental groups were analyzed using oneway analysis of variance (ANOVA), followed by Student-Newman-Keuls (SNK) test.

\section{RESULTS}

Effect of acute and chronic treatments with Saline, and Ketamine on inhibitory avoidance duration and escape latency on elevated $\mathbf{T}$ maze in mice

One way ANOVA revealed significant difference $\left(\mathrm{F}_{3,36}=163.18, \mathrm{p}<0.05\right),\left(\mathrm{F}_{3,36}=\right.$ $110.96, \mathrm{p}<0.05)$ in the inhibitory avoidance duration across treatment groups at the second and third exposures respectively. Post hoc analysis revealed that while acute ketamine significantly decreased inhibitory avoidance duration relative to acute saline group ( $\mathrm{p}<$ 0.05), chronic ketamine significantly increased inhibitory avoidance duration relative to the chronic saline group ( $\mathrm{p}<0.05$ ) at the second and third exposures.

There was significant difference in escape latency $\left(\mathrm{F}_{3,36}=17.35, \mathrm{p}<0.05\right)$ across all treatments groups. While acute ketamine significantly increased escape latency relative to acute saline group, chronic ketamine significantly reduced escape latency relative to chronic saline group $(\mathrm{p}<0.05)$. 


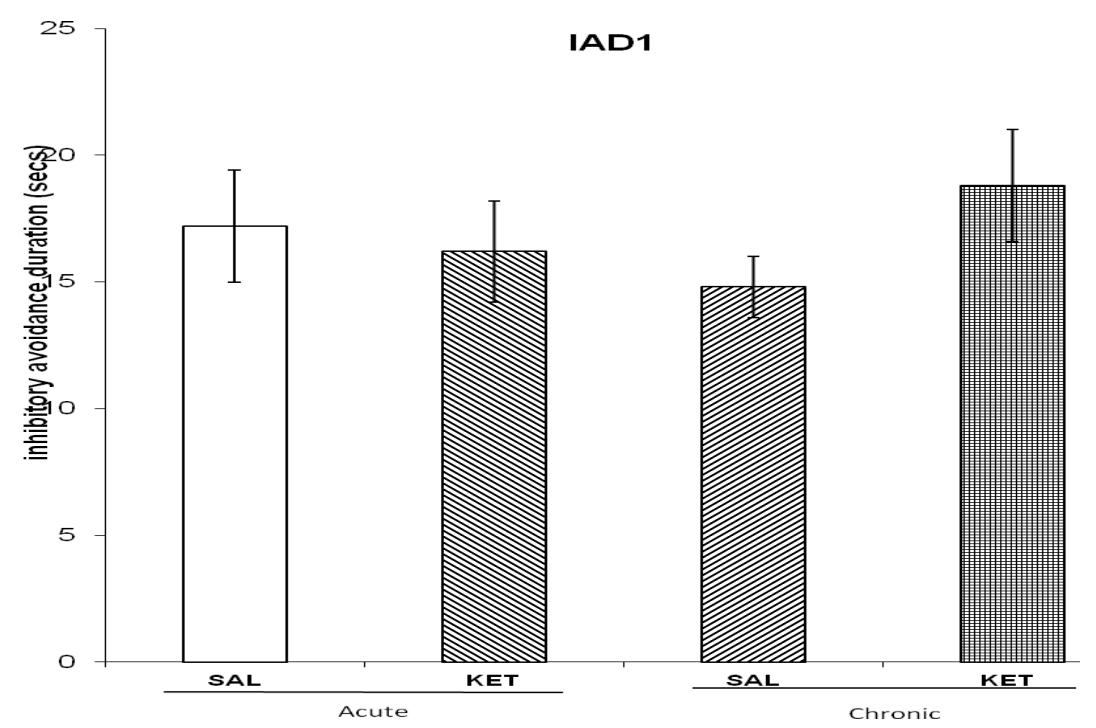

Figure 1: Effect of acute and chronic treatments with Saline (SAL), and Ketamine (KET) on inhibitory avoidance duration on elevated $\mathrm{T}$ maze at first exposure (IAD1) in mice. Each bar represents mean \pm SEM. $(n=10)$.

IAD2

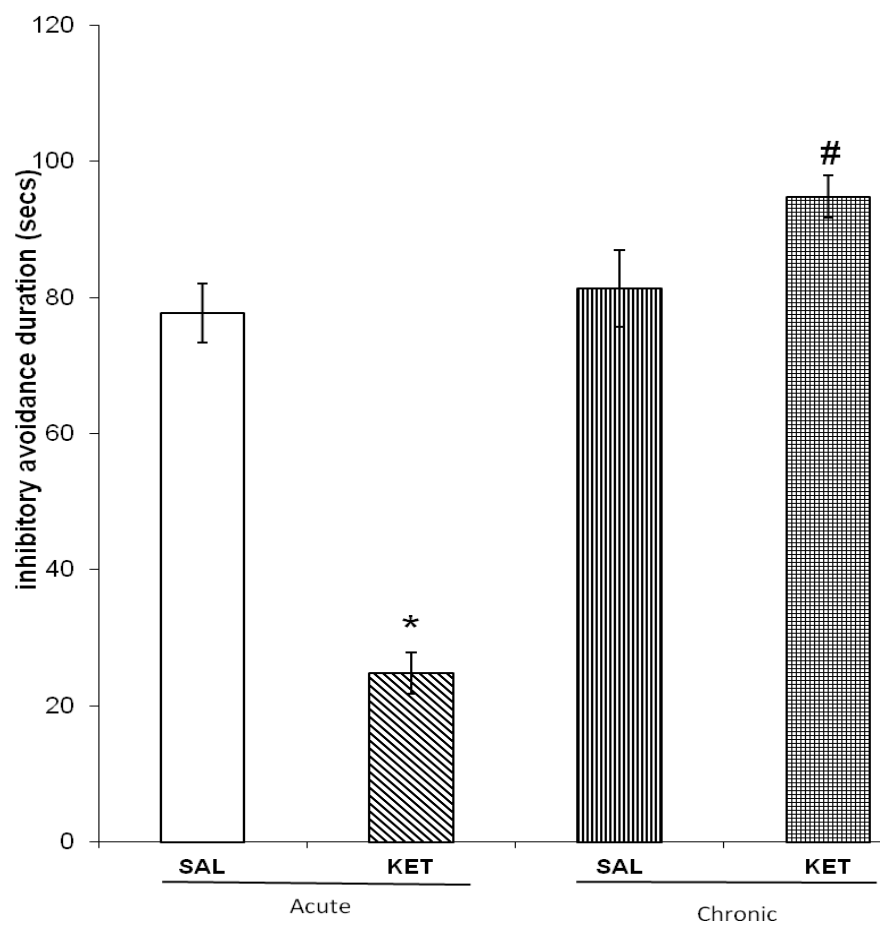

Figure 2: Effect of acute and chronic treatments with Saline (SAL), and Ketamine (KET) on inhibitory avoidance duration on elevated $\mathrm{T}$ maze at second exposure (IAD2) in mice. Each bar represents mean \pm SEM. $(\mathrm{n}=10) .{ }^{*} \mathrm{p}<0.05$ relative to acute saline, ${ }^{\#} \mathrm{p}<0.05$ relative to chronic saline. 
IAD3

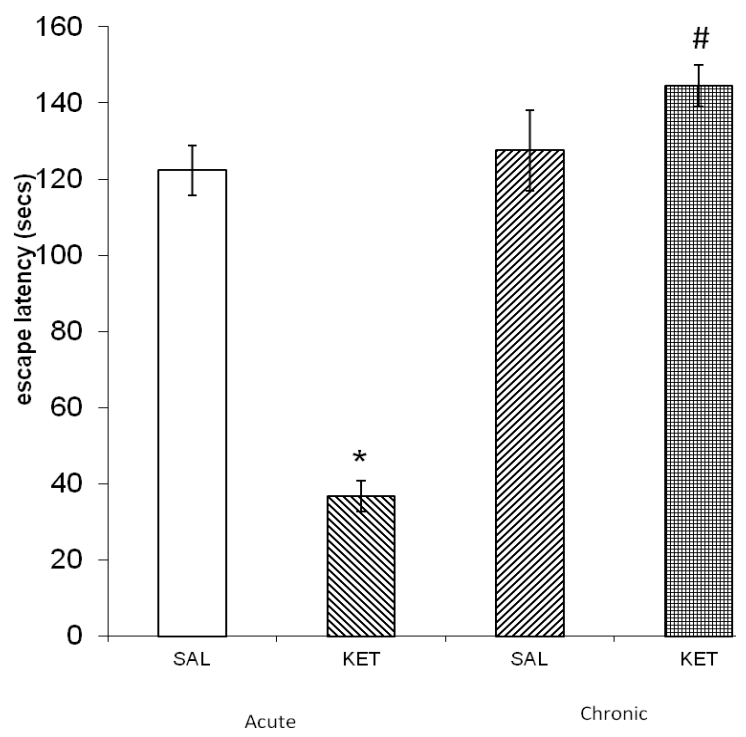

Figure 3: Effect of acute and chronic treatments with Saline (SAL), and Ketamine (KET) on inhibitory avoidance duration on elevated $\mathrm{T}$ maze at second exposure (IAD2) in mice. Each bar represents mean \pm SEM. $(\mathrm{n}=10) .{ }^{*} \mathrm{p}<0.05$ relative to acute saline, ${ }^{\#} \mathrm{p}<0.05$ relative to chronic saline.

ESCAPE

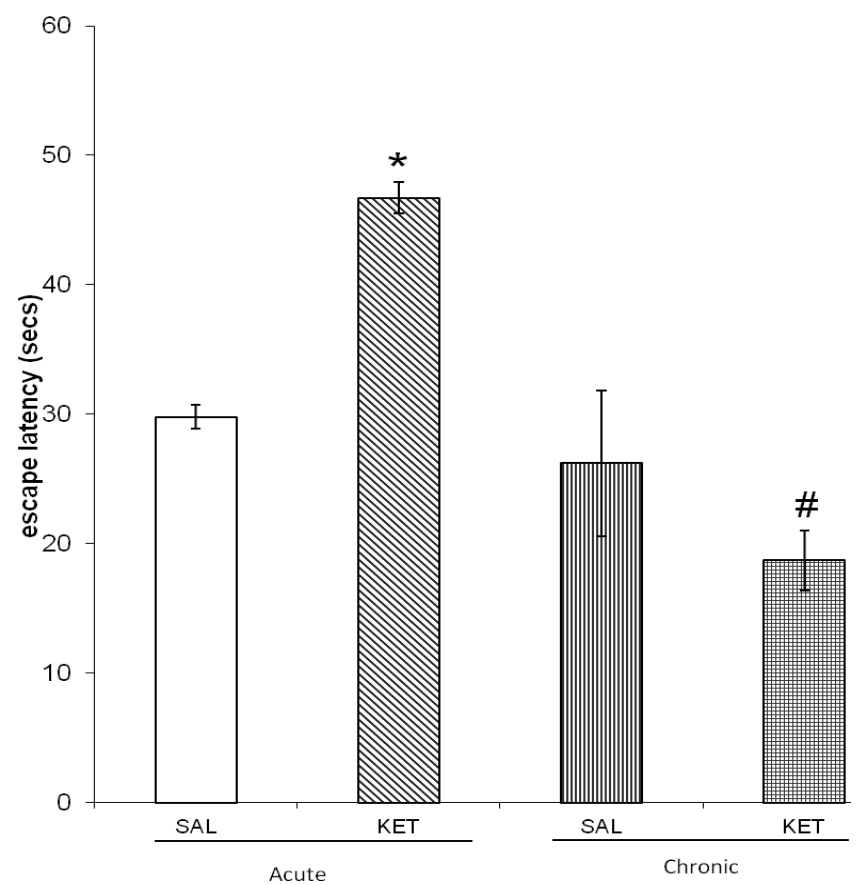

Figure 4: Effect of acute and chronic treatments with Saline (SAL), and Ketamine (KET) on escape latency on elevated T maze in mice. Each bar represents mean \pm SEM. $(n=10) . * p<0.05$ relative to acute saline, ${ }^{\#} \mathrm{p}<0.05$ relative to chronic saline. 


\section{DISCUSSION}

The elevated T maze (ETM) - derived from the widely used elevated X- or plusmaze (Handley and Mithani, 1984 ; Pellow et al., 1985), was introduced as an animal model of anxiety with the aim of simultaneous study of conditioned (related to generalized anxiety disorder) and unconditioned types of fear (related to panic disorder). The inhibitory avoidance duration (IAD) was proposed to represent learned (conditioned) fear (Graeff et al., 1998) while the escape latency (EL) from the open arms into the enclosed arms is a measure of unconditioned fear (Teixeira et al., 2000).

It was observed that acute ketamine - a non-competitive N-methyl,D-Aspartate (NMDA) receptor antagonist significantly suppressed IAD, but increased EL relative to the saline treated group. These results suggest that acute inhibition of NMDA transmission suppressed both conditioned and unconditioned types of fear-related behaviour on the ETM. Several lines of evidence indicate that NMDA receptor ligands modulate anxiety in rodents (ChojnackaWójcik et al., 2001; Wiley et al., 1995). Furthermore the anxiolytic potential of acute treatment with NMDA receptor blockers has been widely reported (Blanchard et al., 1992; Plaznik et al., 1994). In general, antagonism of the NMDA receptor has been linked with anxiolytic behaviour in rodents (Corbett and Dunn, 1991). Furthermore, genetic inactivation of the NMDA receptor NR2A subunit has been reported with anxiolytic effects in mice (Boyce-Rustay and Holmes, 2006). Hence the inhibition of learned and unconditioned types of fear by acute ketamine as reported in this study can be attributed to its NMDA receptor blocking effect (Plaznik et al., 1994). This is supported by reported changes in NMDA transmission following chronic treatments with some anxiolytic drugs (Popik et al., 2000).
Contrary to its acute effect, withdrawal from chronic ketamine increased conditioned and unconditioned fear related behaviours significantly when compared with saline treated groups. Chronic treatment with ketamine has been reported to up-regulate NMDA receptor and increased transmission in the NMDA pathway may occur during the early period of withdrawal from chronic treatment with the NMDA receptor antagonist (Follessa and Ticku, 1996; Economou and Angelatou, 1999; Nagy, 2008). The increase in conditioned and unconditioned type of fear following withdrawal from chronic ketamine treatment can be explained by the increased excitatory transmission in the NMDA pathway. Exposure to fearful stimuli has been reported to be accompanied with increased NMDA receptor expression and mRNA levels in the rat ventral tegmental area and hippocampus (Bartanusz et al., 1995; Fitzgerald et al., 1996). Similarly, positive modulators of NMDA transmission have been reported with anxiogenic properties (Swanson et al., 2005).

\section{Conclusion}

The results of this study clearly demonstrated that NMDA transmission is relevant in the neurobiology of conditioned and unconditioned fear in mice. It can be inferred that down-regulation of NMDA transmission may be a relevant pathway in the various treatment modalities of generalized anxiety and panic disorder, hence may play an important role in the therapeutic mechanism of anxiolytics. Pharmacological modulation of NMDA transmission may be explored for possible improved treatment outcome of anxiety

\section{REFERENCES}

Amiel MJ and Sanjay JM. 2007. Glutamate and anxiety disorders. Current Psychiatric Reports, 9(4): 278-283. 
Bartanusz V, Aubry JM, Pagliusi S, Jezova D, Baffi J, Kiss JZ. 1995. Stress-induced changes in messenger RNA levels of $\mathrm{N}$ methyl-D-aspartate and AMPA receptor subunits in selected regions of the rat hippocampus and hypothalamus. Neuroscience, 66: 247-252.

Boyce-Rustay JM, Holmes A. 2006. Genetic Inactivation of the NMDA Receptor NR2A Subunit has Anxiolytic- and Antidepressant-Like Effects in Mice Neuropsychopharmacology, 31: 24052414.

Blanchard DC, Blanchard JR. Carobrez AD, Veniegas RR, John RJ, Shepherd JK. 1992. MK-801 produces a reduction in anxiety-related anti-predator defensiveness in male and female rats and a gender-dependent increase in locomotor behaviour. Psychopharmacology, 108: 352-362.

Chojnacka-Wójcik E, Kodziñska A, Pilc A. 2001. Glutamate receptor ligands as anxiolytics. Curr Opin Invest Drugs, 2: 1112-1119.

Corbett R, Dunn RW. 1991. Effects of HA1966 on conflict, social interaction, and plus maze behaviours. Drug Dev Res., 24: 201-205.

Davis M. 2011. NMDA receptors and fear extinction : implication for cognitive behavioral therapy. Dialogues Clin Neurosci, 13(4): 463-474.

Economou A, Angelatou F. 1999. Upregulation of NMDA receptors in hippocampus and Cortex in the pentylenetetrazol-induced kindling model of epilepsy. Neurochem Res., 24: 15151522.

Fitzgerald LW, Ortiz J, Hamedani AG, Nestler EJ. 1996. Drugs of abuse and stress increased the expression of GluR1 and NMDAR1 glutamate receptor subunits in the rat ventral tegmental area: common adaptations among cross- sensitizing agents. J. Neurosci., 16: 274282.

Follessa P, Ticku N. 1996: Receptor upregulation. Molecular studies in cultured mouse cortical neurons after chronic NMDA antagonist exposure. $J$ Neurosci., 16(7): 2171-2178.

Garakani A, Mathew SJ, Charney DS. 2006. Neurobiology of anxiety disorders and implications for treatment. Mt Sinai J Med., 73(97): 941-949

Graeff FG, Viana MB. Tomaz C. 1993. The elevated T-maze, a new Experimental model of anxiety and memory. Effect of diazepam. Braz. J. Med. Biol. Res., 26: 67-70.

Graeff FG, Netto FC, Zangrossi H. 1998. The elevated T-maze as an experimental model of anxiety. Neuros. Biobehav. Rev. 23: $237-246$.

Graeff FG. 2002. On serotonin and experimental anxiety. Psychopharmacology, 163: 467 -476.

Graeff FG, Del-Ben C. 2008 Neurobiology of panic disorder: From animal models to brain neuroimaging. Neuroscience and Biobehavioural Reviews, 32(7): 13261335.

Handley SL, Mithani S. 1984. Effects of alpha-adrenoceptor agonists in a mazeexploration model of "fear"'-motivated behaviour. Naunyn-Schmiedeberg's Arch. Pharmacol., 327: 1-5.

Johnson PL, Shekhar A. 2012. An animal model of panic vulnerability with chronic disinhibition of the dorsomedila/ perifrontal hypothalamus. Physol Behav., 107(5): 686-698.

Nagy J. 2008. Alcohol related changes in regulation of NMDA receptor functions. Curr Neuropharmacology, 6(1): 39-54

Pellow S, Chopin P, File SE, Briley M. 1985. Validation of open: closed arm entries in an elevated plus-maze as a measure of anxiety in the rat. J. Neurosci.Meth., 14: 149-167 
Plaznik A, Palejko W, Nazar M, Jessa M. 1994. Effects of antagonists at the NMDA receptor complex in two models of anxiety. Eur. J. Neuropsychopharmacol., 4: 503-512.

Popik P, Wrobel M, Nowak G. 2000. Chronic treatment with antidepressant affect glycine/NMDA receptor function: Behavioural evidence. Neuropsychopharmacol., 39: 2278-2287.

Swanson CJ, Bures M, Johnson MP, Linden AM, Monn JA, Schoepp DD. 2005. Metabotropic glutamate receptors as novel targets for anxiety and stress disorders. Nat Rev Drug Discov., 4: 131144.
Tchernichovski O, Golani I. 1995. A phase plane representation of rat explorative behaviour. J. Neurosci Methods, 62: 2127.

Teixeira RC, Zangrossi JrH, Graeff FG. 2000. Behavioural effects of acute and chronic imipramine in the elevated T-Maze model of anxiety. Pharmacol. Biochem. Behav., 65(4): 571-576.

Wiley JL, Cristello AF, Balster RL. 1995. Effects of site-selective NMDA receptor antagonists in an elevated plus-maze model of anxiety in mice. Eur. J. Pharmacol., 294: 101-107. 